https://helda.helsinki.fi

\title{
Psychoanalytic psychotherapy in Finland
}

\section{Lindfors, Olavi}

2020-04-02

Lindfors , O \& Keinänen , M 2020 , ' Psychoanalytic psychotherapy in Finland ' ,

Psychoanalytic Psychotherapy, vol. 34 , no. 2 , pp. 129-146 . https://doi.org/10.1080/02668734.2020.1836675

http://hdl.handle.net/10138/337088

https://doi.org/10.1080/02668734.2020.1836675

cc_by_nc

acceptedVersion

Downloaded from Helda, University of Helsinki institutional repository.

This is an electronic reprint of the original article.

This reprint may differ from the original in pagination and typographic detail.

Please cite the original version. 
https://doi.org/10.1080/02668734.2020.1836675

Pre-publication version, article published in Psychoanalytic Psychotherapy 2020; 34(2), 129-146

\section{Psychoanalytic psychotherapy in Finland}

Olavi Lindfors* ${ }^{* 1,2}, \mathrm{PhD}$, Docent of Clinical Psychology, Psychoanalyst (IFPS)

Matti Keinänen ${ }^{3-5}$, MD, PhD, Docent of Psychiatry, Accredited MBT-practitioner

(British Psychoanalytic Society), Accredited MBT-supervisor (Anna Freud Centre, London)

${ }^{1}$ Finnish Institute for Health and Welfare, Helsinki, Finland

${ }^{2}$ University of Helsinki, Finland

${ }^{3}$ University of Turku, Finland

${ }^{4}$ University of Jyväskylä, Finland

${ }^{5}$ Policlinic Toivola, Turku, Finland

*olavi.lindfors@ helsinki.fi 


\begin{abstract}
Psychoanalytic psychotherapy is one of the most commonly practiced psychotherapy orientations in Finland. It has secured continuity in the recently renewed university-based educational programs for training psychotherapists, although the proportion of psychoanalytic therapists in relation to other orientations has been decreasing during the past decade. Psychodynamic psychotherapy is reasonably well acknowledged in the Finnish Current Care Guidelines as one option in the treatment of the most common mental disorders, due to recent advances in effectiveness research. There is funding provided by the national insurance system for patients attending long-term rehabilitative psychotherapy. It has been shown to be effective and allows access to up to 3-year long psychotherapy for persons who need help for improving their lowered ability to work or to progress in their studies. However, greater focus on evidence-based short-term treatment models and more strained competition of the public mental health-care resources are expected. In order to survive the struggle, proponents of psychoanalytic psychotherapy need to be active in securing high quality of service delivery and in helping the health care system and political decision makers to recognize the value of our approach. As an example, we present experiences of a successful implementation of the Mentalization-Based Treatment. A viable future of psychoanalytic psychotherapy is highly dependent of continuing high-quality, clinically relevant research and psychotherapist training, as well as organizational cooperation in these areas and in health policy issues.
\end{abstract}




\section{Introduction}

The development of general guidelines for psychotherapy practice and psychotherapist training in Finland dates back to the late 1970's when a national working group was set to estimate the need of psychotherapy services and to provide government health officials quality criteria for psychotherapist training (Pylkkänen et al., 1995). The panel of experts consisted of representatives from our national public health and mental health organizations and authorities, the Social Insurance Institution of Finland, various mental health organizations and representatives of different psychotherapy training organizations and orientations. Psychoanalytic psychotherapy was well represented within the group, along with colleagues, initially, from the training institutes responsible of arranging cognitive, cognitive-analytic, and family therapy education. By 1984 official national recommendations for requirements of psychotherapy training (lower and higher level) were established, after years of collaboration in expert panels. Since 1994 the Health Care Professional Act has regulated the use of the occupational title of psychotherapist. At that time, psychotherapy training in Finland was mostly carried out by dozens of private institutions and organizations. The majority of individual psychotherapist training programs and practising clinicians were then psychoanalytic or -dynamic (these terms usually regarded as synonymous in Finland, while psychodynamic [to be used as the general term in the following] also refers to wider modifications of the treatment models based on psychoanalytic theories).

During the last 25 years, the trend in Finland has been toward increasing varieties of different psychotherapeutic models and greater emphasis on evidence-based evaluation of the treatments, the first evidence-based Current Care Guideline (https://www.kaypahoito.fi/en/) in Finland being given in 1993. The new challenges of the evidence-based medicine (EBM) in mental health care were not met with friendly welcoming by the psychoanalytic and -dynamic societies, but rather indicated resistance and distrust against the dominating research paradigm, based on prioritizing research findings from randomized clinical trials, the assessment of mainly short-term efficacy, and its focus on the effects of manualized therapies under highly controlled conditions. Research like that was considered as poorly suited to the field of psychotherapy and to psychodynamic therapies especially. However, as the pressure to show documented research evidence on the effectiveness of psychotherapies became stronger, the urgent need for outcome research was acknowledged within the Finnish psychoanalytic societies and among psychodynamic clinicians working in the public sector. Hence, a protocol of a large-scale randomized study, the Helsinki Psychotherapy Study (HPS), on the effectiveness of short- and long-term psychodynamic psychotherapies and brief solution- 
focused therapy was initiated at the psychiatric outpatient clinic of the Helsinki University Hospital, the same year that the first Current Care Guideline was given in Finland (Aalberg et al. 1993, Knekt and Lindfors, 2004).

An important phase toward greater acceptance of the need for outcome research and for developing the national psychotherapy services, guided by research evidence, was marked by a Consensus Panel on Psychotherapy, organized jointly by the Finnish Medical Society Duodecim and the Academy of Finland (2006). Several researchers with a psychodynamic clinical background had a major role in organizing the panel and were actively engaged in the working groups. The statement of the panel acknowledged the value of the EBM principles when comparing the effects of different psychotherapies in the treatment of specific psychiatric disorders and for developing psychotherapy services, but also highlighted the need for a diversity of research paradigms, suitable for estimating effectiveness in routine clinical setting and among regular patients with frequently co-morbid psychiatric disorders, and for investigating process-outcome issues.

In 2020, psychodynamic psychotherapy is still one of the most commonly practiced psychotherapy orientations in Finland. However, its previously relatively strong position in academic psychiatry and psychology has been decreasing, and the continuity of its role within the psychotherapy service system (especially concerning long-term psychotherapy) has recently been challenged. A major social and health care reform is shortly to be initiated in Finland. Greater focus on EBM models and more strained competition of the mental health care resources allocated to privately or publicly provided short-term and long-term therapies and to different treatment models is expected. Thus, more work needs to be done for ensuring the continuing role of modern psychoanalytic thinking and psychodynamic therapies in the public mental health services.

\section{Psychotherapist training in Finland}

An update of a decree concerning health care professionals, given in 2010, set new requirements for receiving the protected occupational title of psychotherapist (i.e. an independent health care occupation). The aims were to unify and improve the quality criteria for psychotherapist training and to implement the training in the public educational system of universities. Since 2012, basic psychotherapist training can be organised only by a university or by a university together with some other organisation with psychotherapeutic and educational expertise. The university organising 
psychotherapist training must possess responsibility for providing education in psychology or medicine. There is also a national advisory network of psychotherapy training, covering all the universities arranging the training.

The competence required for practising as a psychotherapist is acquired by studies of at least 60 credits (carried out usually part-time, during 3-4 years), consisting of the study modules of theoretical and clinical studies, psychotherapeutic work with patients under job supervision, personal psychotherapy and a small-scale thesis. The competence needs to be proved by a competence-based test or portfolio.

The psychotherapy training programs are comparable to continuing education organised for health care professionals and require prior experience in the field of mental health or equivalent fields, as well as an applicable background education, usually in health or social sciences. The requirement for being approved for the training is work experience of at least two years in mental health services or corresponding service and that the person has before the psychotherapist training: 1) taken an applicable higher level university degree or a comparable degree in social and health studies in a university of applied sciences; the training must include or one must have completed, in addition to it, a total of 30 credits of studies in psychology or psychiatry; or 2) completed post-secondary nurse education and specialisation in psychiatry; or 3) completed other training abroad corresponding to the above requirements.

Thus far, at least some psychodynamic psychotherapist training programs (separately for individual psychoanalytic/-dynamic psychotherapy for adults, adolescents, and children; psychoanalysis; and psychoanalytic art psychotherapy) have been arranged or are being planned at all the six universities which offer psychotherapist training in Finland. However, there are great differences in the extent to which psychodynamic training has been accepted as an educational program in different universities. The way the training programs are administered between the university and the collaborative training institutes also vary between the different universities. At all the universities where psychodynamic psychotherapy training programs have been organized (Eastern Finland, Helsinki, Oulu, Tampere, Turku), the teaching is mainly carried out by teams of the cooperating psychodynamic training institutes, which are relatively autonomous also in planning the curriculum. The university departments in charge of the administration represent usually adult or child psychiatry or psychology. At the University of Helsinki, the training programs are coordinated jointly by the departments of psychiatry and psychology. 
Psychotherapist training is not financially supported by government budget like other continuing university education for health care professionals, and thus the training becomes rather costly for the students, as their payments are the only way to finance the training. This has been a major concern for those arranging and participating in the training as the training can only be an option for those who can afford it, unlike, e.g. for those specializing in the medical profession, for whom statesubsidized training in universities is available. The higher costs of psychodynamic training (due to the more extensive personal psychotherapy required and relatively small training groups) compared to the majority of other programs, are a further challenge for attracting applicants. Apart from the cost issues, the move of psychotherapy training to universities has succeeded rather well, and as far as known, without major threats to the integrity of the programs. Although in some programs the university administration has increased administrative strains, there are also benefits related to the research-oriented environment, increased quality-control of all psychotherapist training (in contrast to the previous era with possibly "wild", unregulated or poorly controlled training institutes), and better possibilities for contact between different schools of psychotherapy.

In addition to the above basic psychotherapy training programs, the universities can also arrange or grant the permission to the cooperating partners to arrange higher level psychotherapy training to psychotherapists who seek to become qualified as trainers and supervisors of the respective therapy form that they have initially been trained in. As in the case of basic psychotherapy training, the university has the responsibility for quality control of the training. In practice, most of these programs are arranged relatively autonomously by the training institutes. There are several psychoanalytic/dynamic training institutes for adult, adolescent and child psychotherapy in Finland which have been actively engaged in university-based psychotherapist training cooperation and other further therapist training. Majority of these institutions belong to the network of the European Federation of Psychoanalytic Societies in the Public Sector (EFPP), and most of them are also attached to other international psychoanalytic or -dynamic organizations and apply their standards in training. The role of the psychotherapy training institutes is naturally also important in assuring continuing cooperation in coordinating training and organizing professional interaction between the members of the respective institutes, arranging further theoretical and clinical education, and advancing research and publication activities in the area. 


\section{Psychotherapists at work}

About a decade ago a large survey on psychotherapists and psychotherapy services in Finland was conducted among the registered psychotherapists (Valkonen et al., 2011). The number of the persons with the occupational title of psychotherapist was then about 5000 , of whom about a quarter were not active in clinical practice. The respondents $(n=2366)$ were mostly $(78 \%)$ women, their age on average was 53 years, and the median age they had completed their psychotherapist training was 44 . The largest group by initial profession were psychologists (33\%), followed by psychiatric nurses (26\%) and medical doctors (16\%). More than half of the psychotherapists had been trained in a psychodynamic or -analytic training institute. The proportion of family therapists was $36 \%$, cognitive-behavioural therapists $15 \%$, crisis or trauma therapists $9 \%$ and solution-focused $7 \%$. About one in five had received psychotherapy training targeted for adolescents or children. About a third of the therapists operated mainly in private practice and a half in the public health care sector and many also partly in private practice. Those in full-time private practice had available on average 24 therapy sessions a week and those in part-time practice (24\%) 15 sessions. The patients of psychodynamic therapists usually attended long-term psychotherapy (at least weekly sessions and duration for at least one year). Majority of their patients received subsidy for their therapy from the Social Insurance Institution of Finland ('Kela'), i.e., they attended rehabilitative psychotherapy.

\section{Mental health services and access to psychotherapy in Finland}

A citizen can seek psychotherapy in Finland through many routes: privately from individual service producers, i.e. private psychotherapists or companies proving psychotherapy services (without seeking outside funding or by means of privately acquired insurance); from a psychotherapist who is a medical doctor (with a minor national health insurance coverage); public healthcare, usually from specialised psychiatric care (mostly short-term therapies purchased from private sector or brief internet-based therapies; as well as through limited access to evidence-based treatment models produced within the public health care). One can also apply for rehabilitative psychotherapy (i.e., long-term psychotherapy) reimbursed by the Social Insurance Institution of Finland. Mainly brief therapy or psychosocial support can also be accessed (depending on the employer's health care plan) via occupational health care, primary health care centres (e.g. psychosocial support by nurses providing counselling for patients with depression), and some third sector organisations. Accordingly, the system is rather complex from the client's perspective. 
The municipalities are responsible for arranging public mental health services in Finland and they can organize psychotherapy services as part of their other social and health care services or acquire services from the health care district or from private companies. Although psychotherapy has not specifically been mentioned in legislation as a type of treatment which needs to be offered for citizens, adequate psychiatric treatment based on the individual's needs is required. Recently, however, the Council for Choices in Health Care in Finland (PALKO/COHERE, 2018) gave a recommendation on psychotherapeutic and psychosocial services, indicating that "Empirically supported psychotherapies and psychosocial treatment and rehabilitation methods need to be included as service choices belonging to goal-directed treatment and rehabilitation at all phases of them." The Council is a permanent body appointed by the Government that works in conjunction with the Ministry of Social Affairs and Health and it defines the service choices at a general level. The recommendation was motivated by the overall evaluation that access to psychotherapy and other psychosocial interventions in Finland, at primary health care level, as well as at psychiatric special level, is often delayed due to the present service system being unduly complex. Also, the availability of psychotherapy in Finland is insufficient and geographically unevenly distributed (Valkonen et al., 2011; Vuorilehto et al., 2016).

The new the mental health strategy for the years 2020-2030 of the Ministry for Social and Health Affairs aims to improve the availability of psychotherapies and preventive and therapeutic psychosocial interventions in primary health care (Vorma et al., 2020). In addition, the cooperation structure of primary health care and specialised medical care is planned to be strengthened (to be coordinated by the five major university hospital districts) to improve the detection of mental disorders so that support or treatment can be started early and with greater equality of citizens in different parts of the country. One of the main priorities of the program stresses the importance of broad-based and coordinated services that correspond to people's needs. However, it is not yet known how the coming social and health care reform will change the responsibilities, resources and administration of psychotherapy delivery within the public and private sector. Instead of the numerous municipalities, the main responsibility for organizing health care in the future has been planned to be given to self-governing regions (counties) that are larger than municipalities. Counties will carry out some of their tasks in cooperation with other counties. The public sector will be the primary service provider in the counties, with the private and third sectors serving as supplementary service providers. The reform has been described as being based on evidence-based information and knowledge-based management, and it intends to advance integration in terms of healthcare and social 
services and basic-level and specialised medical level services. As in any major reform, there are possibilities and threats involved. Concerning the latter, at a previous planning phase of the reform (2018) the continuity for the funding of rehabilitation psychotherapy was challenged, which caused concerns and anxieties among both clinicians and clients. However, individual citizens, several experts and professional organizations (including the EFPP in Finland) reacted to these plans by signing petitions and negotiating with the responsible authorities and politicians, highlighting the advantages of the well-functioning and effective present system (Tikkanen, 2018), and managed, at least temporarily, in blocking or postponing the attempts by several years. At present, however, the details of the future plans are still open.

Some kind of outcome monitoring and reporting of access, waiting times and recovery rates is planned to be developed within the Finnish psychotherapy services. On a general level, the Finnish Institute for Health and Welfare (THL) has the responsibility to collect information, provide statistics and guidance for implementing indicators on the quality of mental health services. Recently one of the main service producers, the Hospital District of Helsinki and Uusimaa (HUS psychiatry) launched a quality register project which, for the first time in Finland, will collect a data base to be used for developing outcome monitoring of both internet-based and face-to-face therapies provided by the service system and acquired from private practitioners. At the moment the system offers voluntary participation for therapists working within the rehabilitative psychotherapy system. There is an ongoing discussion on how to secure that the quality register, if adopted among all kinds of shortand long-term therapies, should be developed in line with the collaboration between the Current Care Guideline system and health care, for the benefit of patients and practicing clinicians.

Historically, a distinction was made in Finland concerning the legislation on health care, covering psychotherapy conceptualized as a treatment (services produced by the health care) and legislation concerning rehabilitation, covering psychotherapy conceptualized as rehabilitative psychotherapy (organized by the Social Insurance Institution of Finland). The latter has grown to be a major producer of officially organized and reimbursed psychotherapy, delivered by trained psychotherapists in Finland. There have also been side-effects due to the distinction between psychotherapy as treatment and psychotherapy as rehabilitation, as the relatively well-functioning and effective rehabilitative psychotherapy system seems to have been used by the public health care to compensate the insufficiency of its own psychotherapy service production (Tuulio-Henriksson et al., 2019). Accordingly, part of the patients who are referred to rehabilitative psychotherapy might have benefitted from shorter therapies if those would have been available earlier to a greater extent. 


\section{Long-term psychotherapy provided as rehabilitative psychotherapy}

Rehabilitative psychotherapy organized by the Social Insurance Institution of Finland has been available by application since 1992 for persons between 16 and 67 years of age whose ability to work or study has been impaired due to a mental health disorder (Tuulio-Henriksson et al., 2014). Before the rehabilitative psychotherapy can begin, the patient needs to have undergone at least a three-month active treatment period, based on appropriate treatment principles, within private or public health care system. If the initial treatment, based on medication and/or psychological help, has been insufficient, a person may qualify for the reimbursed psychotherapy. The purpose of rehabilitative psychotherapy is to improve the clients' ability to work or to help them progress in their studies, remain economically active, or enter or return to working life (Kela, 2020). It is by far the most used channel for referring patients to psychotherapy in Finland, enabling annually (in 2018) about 44000 persons to have significant financial support for their psychotherapy (Kela, 2019). The number of patients seeking psychotherapy within the system has more than tripled during the last 10 years. The majority of the patients $(88 \%)$ have either depressive or anxiety disorder as their main diagnosis, recurrent major depressive disorder being the most usual diagnosis. The number of patients with diagnosed personality disorder among the rehabilitative psychotherapy patients is surprisingly low, and probably reflects the expectation of the referring psychiatrist that it would have a negative effect on the application. On average, three quarters of the patients are women and aged 20-44 years.

Since 2011 the client has had a subjective right for rehabilitative psychotherapy if the criteria for it apply. In case a psychiatrist, based on thorough psychiatric evaluation, concludes by a statement that it is necessary for a person to have access to rehabilitative psychotherapy, the support can be granted, for one year at a time, up to 80 sessions a year, and altogether for up to 200 therapy sessions, during a 3-year time period. About a third of the patients attend the therapy for one, two, or three years' duration (Tuulio-Henriksson et al., 2014).

At present, the compensation for the patient is about 57 euros per session (the usual fee of psychotherapists being usually 80-100 euros). The funding of the system comes mostly (55\%) from the social security payments of employers and employees, and the rest from the state budget. Rehabilitative psychotherapy can be provided in the form of individual, group, family or couples psychotherapy. All qualified psychotherapists approved by the Social Insurance Institution can provide the treatment and the client has the freedom to choose among the available therapists and the 
therapy orientation best suited to him/herself. At the moment there is a shortage of trained psychotherapists due to the increase in referrals to rehabilitative psychotherapy. Individual psychodynamic psychotherapy is one of the most used forms of rehabilitative psychotherapy in Finland.

In addition, a separate funding system for psychotherapy by the Social Insurance Institution, is available for persons under the age of 65 who have a chronic, long-term medical condition or disability, and functional disability and who need psychological help for coping with everyday life. A thorough rehabilitation plan is needed for this kind of demanding level medical-psychosocial rehabilitation, which can be based on individual or group psychotherapy, and be reimbursed in its entirety.

The functional benefits of long-term psychotherapy, carried out as rehabilitative psychotherapy have been shown by register-based studies and have indicated that approximately a third of those who, at the baseline, were not active in the labour market because of health reasons, re-entered the labour market after the rehabilitation (Aaltonen and Lind, 2004). A more recent register study showed that $80 \%$ of the patients who were employed at the beginning of the therapy, continued in work also after the therapy (Tuulio-Henriksson et al., 2019).

Evidence for the effectiveness of long-term psychodynamic psychotherapy in comparison to shortterm therapies has been accumulating in the Helsinki Psychotherapy Study (HPS) since its patients were recruited between 1994-2000, and during the 10-year follow-up from the beginning of the treatments (Knekt and Lindfors, 2004, Knekt et al., 2011, 2012, 2016). In HPS, 326 outpatients, aged 20-45 years, with anxiety or depressive disorder, were randomly assigned to solution-focused therapy (SFT, $\mathrm{n}=97$ ), to short-term psychodynamic psychotherapy (SPP, $\mathrm{n}=101$ ), and to long-term psychodynamic psychotherapy (LPP, $n=128$ ). Additionally, patients self-selected for psychoanalysis $(\mathrm{PA}, \mathrm{n}=41)$ were also included in a quasi-experimental arm of the study. Although the change process was initially slower in LPP, greater long-term effects than in short-term therapies appeared as there was lesser use of auxiliary psychiatric treatment during the entire follow-up, and more extensive decrease of symptoms and improvement of work ability. At the end of the 5-year follow-up the initial 12-20 protocol-based sessions of the short-term therapies became on average 3-folded when auxiliary therapy sessions were counted, and by the 10-year follow-up more than 5-folded, as the patients randomised to short-term therapies had cumulatively attended, on average, more than 100 therapy sessions (Knekt et al., 2011, 2016). At the 10-year follow-up altogether $81 \%$ of the patients receiving 
LPP were in remission and 67-69\% of those who initially received SFT and SPP, respectively. It can be estimated that in the event that all the 198 individuals allocated to the short-term therapy groups would have received LPP, about 25 of those not remitted would have achieved remission, albeit with greater costs (Knekt et al., 2016). PA appeared to produce somewhat greater long-term effects in personality functioning than LPP (Lindfors et al., 2019). The study also showed that factors affecting sufficiency of and suitability for treatments of different length can be identified and used for allocating resources with greater precision to meet the needs, preferences and characteristics of individual patients. Patients with better pre-treatment psychological dispositions seem to benefit often from short-term therapy sufficiently, whereas patients with worse predispositions more often need longterm therapy or some other treatment to recover (Laaksonen et al., 2013; Lindfors et al., 2014; Knekt et al., 2014, 2017; Heinonen et al., 2016).

The findings of HPS, especially on the more sustained effects of long-term psychodynamic therapy, have been acknowledged both nationally and internationally, and in addition to findings from other major effectiveness studies and meta-analyses focused on psychodynamic therapies (e.g. Leichenring et al., 2015, Fonagy, 2015) have contributed to and strengthened the evidence-base of LPP in Finland and globally. In the following we will briefly describe how the evidence-based current care guideline system is organized in Finland and what is the present status of psychodynamic therapies as recommendable treatments for different psychiatric disorders in those guidelines.

\section{Provision of Current Care Guidelines}

The Current Care Guidelines in Finland are developed by the Finnish Medical Society Duodecim in cooperation with the medical specialist associations (Current Care Guidelines, 2020, https://www.kaypahoito.fi/en/). The Finnish Guideline office is a founding member of the Guidelines International Network (G-I-N, https://g-i-n.net). The majority of the recommendations are targeted on the treatment of specific disorders. The Current Care office staff consists of part-time editors for each recommendation, information specialists, technical editors and secretaries compiling patient versions and educational material. The work is carried out by the Current Care working groups (volunteer health care top professionals) who are responsible for carrying out systematic literature searches, and for producing the guidelines in cooperation with Current Care editors, who operate as method experts. Prior to its completion, the guideline is circulated to specific interest groups for their 
consideration, after which any resulting comments are discussed and the guideline edited and specified, if necessary.

At present there are altogether about a dozen Current Care Guidelines on mental health disorders, from a total of about a hundred Guidelines on the treatment, prevention or clinical assessment in diverse medical conditions. The strength of the evidence is graded from A to D, level A indicating strong evidence, requiring several methodologically sound randomized controlled trials with findings showing similar effects, level B indicating moderate evidence (at least one RCT or several methodologically sound and applicable non-randomized studies), $\mathrm{C}$ indicating at least one methodologically sound non-randomized trial, and D being based on expert opinion.

There are altogether nine guidelines covering adult mental disorders: ADHD, alcohol-related disorders, anxiety disorders, bipolar disorder, borderline personality disorder, depression, eating disorders, PTSD, and schizophrenia (Current Care Guidelines, 2020). Psychodynamic psychotherapy is considered as one potential treatment option in four guidelines.

In the guidelines for the treatment of depression, the strength of graded research evidence for psychodynamic psychotherapy varies from A, with several high-quality RCT studies available on the effectiveness of short-term psychodynamic therapy as a treatment of depression at the acute phase, to B-level, on the effectiveness of long-term psychodynamic psychotherapy for the treatment of chronic and complicated depression and for persons for whom short-term therapy is estimated to be insufficient. In the acute treatment phase of depression, the guideline directs clinicians to offer the patient either some psychotherapy with shown effectiveness (cognitive-behavioural, interpersonal, psychodynamic or problem-solving), or antidepressant medication, or both, and informs that the simultaneous use of medication and psychotherapy is recommended especially in the more severe forms of depression. Accordingly, psychotherapy can also be provided without concurrent medication. The internet-based therapies and online therapies provided with remote access are one evidence-based option to be used.

In the recently updated guidelines for borderline personality disorder (BPD), the degree of evidence for mentalization-based therapy (MBT) for adults was upgraded from B-level to the best A-level: MBT is effective in the treatment of BPD and intensive outpatient MBT is as effective as day hospital MBT (Borderline Personality Disorder. Finnish Current Care Guidelines, 2020). It is very significant that MBT is now graded efficient in the treatment of BPD as a whole, not only in respect to some 
symptoms of BPD. As far as we know, MBT for adults in the treatment of BPD is now graded in the Current Care Guidelines at the A-level for the first time in the world.

Further, the B level grading of another manualized treatment model for BPD, transference-focused therapy (TFP), does not differ from other major therapy options in this diagnostic group, while other psychodynamic formats are graded lower due to lesser research evidence available. A recent Cochrane systematic review and meta-analysis has further supported equal benefits of especially MBT and Dialectic Behaviour Therapy compared to treatment as usual (Storebo et. al., 2020).

In the guidelines for anxiety disorders, psychodynamic psychotherapy is graded B in the guidelines for the treatment of social phobia and $\mathrm{C}$ in the treatment of panic disorder and generalized anxiety disorder, and accordingly do not have similarly strong evidence-base as cognitive-behavioural therapies. In the recently updated guidelines for schizophrenia, supportive psychodynamic psychotherapy is acknowledged a $\mathrm{C}$ grading of evidence.

In conclusion, psychodynamic psychotherapy is an acknowledged option to be used especially in the treatment of patients with depression, borderline personality disorder and anxiety disorders according to the Finnish Current Care Guidelines available at present. Due to lack of research or due to no shown benefits in comparison to treatment as usual, psychodynamic psychotherapy is not specifically mentioned as a potentially recommendable option (or has been allowed a grading D), in the treatment of patients with ADHD, eating disorders, PTSD, and bipolar disorder. Of the above guidelines, the eating disorder guideline from 2014 clearly needs updating due to missing new research.

The Current Care Guidelines are considered as authoritative comments aimed to improve the quality of care and to decrease inconsistencies between treatment practices. The guiding principle in the Finnish health care is to provide broad-based and coordinated services, acknowledging that evidencebased treatments are best served when they are personalized to meet the individual client's needs. In general, the guidelines are well known by health care decision makers and appreciated as a source of information. The personal experience of both authors of this review, based on long-term membership in the Current Care Guideline panels (working groups) (OL, guideline panel on depression, 20042019, and MK, guideline panel on borderline personality disorder, since 2004), is that the work is carried out professionally, by clearly defined criteria and taking into consideration relevant needs of clinical practice, and without (at least not explicitly expressed) political tendencies of excluding or discriminating any psychotherapeutic orientation in the evaluation process. However, it varies how 
the guidelines are utilized in the self-governing health care service regions. There are some tensions and different opinions on how to prioritize different working models of psychotherapeutic treatments and locally there may be tendencies to favour some therapeutic models over others or to rely more heavily on the medical vs. the contextual model of treatment. It is still an open question how the social and health care reform will affect the situation in Finland.

\section{How should psychodynamic psychotherapy adapt in the future?}

Although there is increasing evidence of the effectiveness of psychodynamic psychotherapies in a range of psychiatric disorders (Fonagy, 2015) and the suggested applicability of modern psychoanalytic thinking and concepts for improving patient care and management (Yakeley, 2018), and although the psychodynamic approach is relatively well-established in Finland, ensuring continuity for the appreciation of psychotherapeutic diversity within the public health care and rehabilitation is a challenging task.

In order to survive the struggle, proponents of psychodynamic psychotherapy need to be active in securing high quality of service delivery and in helping the health care system and political decision makers to recognize the value of our approach. Advancing high quality education for psychotherapists, further training of clinicians in evidence-based psychodynamic models, developing their implementation in health care, publication activities, refining the theoretical base of the approach, participation in the Current Care Guideline work, being active in public media, and organizational activities in proposing reforms and commenting proposed changes in the legislation on mental health and psychotherapy, are some of the ways the Finnish psychodynamic practitioners and researchers have aimed to face the challenges.

We will focus here only on presenting how further training of clinicians and the implementation of an evidence-based psychodynamic model for persons with borderline personality disorder has been successfully initiated, by presenting actions concerning the MBT as an example. BPD patients are frequently treated within the psychiatric special level, and thus the evidence-based psychodynamic models are well suited to the needs of public health care. 


\section{Advancing Mentalization-based treatment in the Finnish mental health care}

Mentalization is the ability to understand the mental state, of oneself and others, that underlies overt behaviour. Mentalization can be seen as a form of imaginative mental activity that lets us perceive and interpret human behaviour in terms of intentional mental states (e.g., needs, desires, feelings, beliefs, goals, purposes, and reasons). So mentalization is defined as the process by which we implicitly and explicitly interpret the actions of oneself and others as meaningful on the basis of intentional mental states.

MBT is a psychodynamic, integrative form of psychotherapy, bringing together aspects of psychoanalytic, cognitive-behavioural, systemic and ecological approaches. MBT was developed, manualised and documented to be an evidence based multimodal treatment model, designed originally for individuals with borderline personality disorder (BPD) by Anthony Bateman and Peter Fonagy (Bateman and Fonagy, 1999, 2008, 2009, 2016, 2019, Laurenssen et al., 2018). The main object of treatment is that patients increase their mentalization capacity, which in turn improves affect regulation as well as strengthens the capacity to interpersonal relationships. Later, a range of other mentalization-based treatments directed at children (MBT-C), families (MBT-F) and adolescents (MBT-A), have been developed.

Since the beginning of the new millennium there have been in Finland some individual mental health workers who have applied MBT-techniques in their work. In order to assist the implementation of MBT to clinical practice professor Anthony Bateman (UCL, London) was invited to hold MBTconferences in Finland. The interest in MBT has gradually grown up here. The turning point into the wider use of mentalizing model in public mental health services in Finland was in 2017. Then a group of mental health professionals interested in MBT and already using mentalizing techniques in their work decided to arrange the first Finnish congress of MBT in Turku, Finland, together with Turku Summer University. This congress was a success having about 150 participants. At the same time the Finnish Mentalization Association was founded, consisting now of about 180 mental health professionals. The board of the Finnish Mentalization Association has decided to arrange every other year mentalization congress, so the second congress was in November 2019.

The Finnish Mentalization Association has two aims 1) to promote paying attention to the mentalizing viewpoint in different activities of the whole society and 2) to advance to use of mentalization based therapy techniques in Finnish mental health services. The members of the Finnish Mentalization 
Association use MBT techniques in various ways in their treatment work. Thus far the whole MBTtreatment program according to the Anna Freud Centre model has been implemented in one public mental health care unit, Järvenpää Psychiatric out-patient service nearby Helsinki (Keinänen et al., 2017). Along with it, there is an interest in developing MBT-teams also in other mental health services in Finland.

The MBT education work in Finnish Mentalization Association is closely connected to the cooperation with the Anna Freud Centre (AFC) MBT education system. It follows the same rules as AFC has so that our education in Finland will be compatible to that of AFC. Thus, we founded in 2019 MBT Finland (being a part of Finnish Mentalization Association) for developing and arranging MBT education in Finland in cooperation with AFC. At the moment we are planning the official MBT education program connected to AFC to educate new internationally accredited MBT practitioners for mental health services in Finland.

There is also other mentalization-based treatment education going on, which is not officially connected to Finnish Mentalization Association, both as mentalization treatment courses (e.g. Keinänen and Martin, 2019) or as a separate part of other psychotherapy education programs, e,g, in several psychodynamic psychotherapy education programs. In accordance with the recent A level grading of MBT (Borderline Personality Disorder. Finnish Current Care Guidelines 2020) there is an urgent need to train practitioners to implement MBT in the Finnish mental health treatment services.

The verification of MBT as an effective EBM treatment of BPD in Finland is important so that we can justify MBT-program implementation also to new psychiatric services in addition to Järvenpää Psychiatric out-patient service and to establish the use of MBT broadly in Finnish mental health services, not only in the form of MBT-program, but also in using of various MBT techniques as an essential working tool by mental health workers in various psychiatric services. At the moment we are rather confident that the implementation of mentalization-based treatment will proceed favorably within the Finnish mental health practice service. However, of course there are challenges, e,g. due the lack of economic resources.

\section{Securing a viable future for psychoanalytic psychotherapy globally}

Our opinion is that viable future of psychodynamic psychotherapy is highly dependent of continuing high-quality, clinically relevant research and psychotherapist training, as well organizational 
cooperation in the areas of research funding and health policy issues. The EBM model guiding efficacy and effectiveness needs to be complemented by an increasing focus on the principles of personalized medicine, such as determining patient factors relevant for the suitability of the psychodynamic therapies, provided as short-term or as long-term treatment (Knekt et al., 2016), and increasing international cooperation, e.g., by conducting joined, individual participant-level data based meta-analyses on these therapies (Driessen et al., 2018). Likewise, process-outcome studies looking at the mechanisms of change relevant for psychodynamic therapies (e.g. De Meulemeester et al., 2017) and investigating determinants of successful implementation of the psychodynamic treatment models within the public health care (Bales et al., 2017), are needed. In addition to cooperation concerning common interests within various research organizations, such as the Society for Psychotherapy Research (e.g. ongoing collaborative research on psychotherapist training, Orlinsky et al., 2015), more structured discussions and workshops on how to respond constructively to the pressures of the EBM model need to be arranged in psychoanalytic and psychodynamic congresses. Practice-research networks may be valuable for attracting greater number of clinicians to participate in practice-relevant research. By sharing experiences and cooperating in these areas we can be more confident in the continued development of our therapeutic approach. 


\section{References}

Aalberg, V. et al. Helsingin psykoterapiaprojektin tutkimussuunnitelma [Unpublished research plan for the Helsinki Psychotherapy Study]. Psychiatric outpatient clinic, Helsinki University Hospital, 1993.

Aaltonen, T., Lind, J. Miten työkyky muuttuu Kelan tukeman psykoterapiakuntoutuksen jälkeen? Rekisteriseuranta Kelan psykoterapiaa saaneiden työ- ja opiskelukyvystä vuosina 2002-2004. [Changes in working ability after psychotherapeutic rehabilitation. A register-based follow-up study of the working and studying abilities of persons receiving psychotherapy provided by Kela during 2002-2004]. Helsinki: Kela, Sosiaali- ja terveysturvan tutkimuksia 95, 2008.

Bales, D. L., Timmani, R., Luyten, P., Busschbach, J., Verheul, R., Hutsebaut, J. Implementation of evidence-based treatments for borderline personality disorder: The impact of organizational changes on treatment outcome of mentalization-based treatment. Personality and Mental Health 2017; DOI 10.1002/pmh.1381.

Bateman, A., Fonagy, P. Effectiveness of partial hospitalization in the treatment of borderline personality disorder: a randomized controlled trial. Am J Psychiatry 1999; 156: 1563-9.

Bateman, A., Fonagy. P. 8-year follow-up of patients treated for borderline personality disorder: mentalization-based treatment versus treatment as usual. Am J Psychiatry 2008; 165: 631-8.

Bateman, A., Fonagy, P. Handbook of Mentalizing in Mental Health Practice. Second Edition. American Psychiatric Association Publishing, USA, 2019.

Bateman, A., Fonagy, P. Mentalization-based treatment for personality disorders: A practical guide. Oxford: Oxford University Press, 2016.

Bateman, A., Fonagy, P. Randomized controlled trial of outpatient mentalization-based treatment versus structured clinical management for borderline personality disorder. Am J Psychiatry 2009; 166: $1355-64$.

Borderline Personality Disorder. Current Care Guideline [in Finnish: Epävakaa persoonallisuus. Käypä hoito -suositus. Suomalaisen Lääkäriseuran Duodecimin ja Suomen Psykiatriyhdistys ry:n asettama työryhmä. Helsinki: Suomalainen Lääkäriseura Duodecim, 2020 (referenced 8.6.2020). www.kaypahoito.fi

Current Care Guidelines. Current Care Guidelines are independent, evidence-based clinical practice guidelines. [Home page of the Current Care Guidelines Finland]. 2020, www.kaypahoito.fi

De Meulemeester, C., Vansteelandt, K., Luyten, P., Lowyck, B. Mentalizing as a mechanism of change in the treatment of patients with borderline personality disorder: a parallel process growth modeling approach. Personality Disorders: Theory, Research and Treatment 2017, 9: 22-29.

https://doi.org/10.1037/per0000256

Driessen, E., Abbass, A., Barber, J. P., Connolly Gibbons, M. B., et al. Which patients benefit specifically from short-term psychodynamic psychotherapy (STPP) for depression? Study protocol of a systematic review and meta-analysis of individual participant data. BMJ Open 2018; 2018;8:e018900. doi:10.1136/bmjopen-2017-018900.

Heinonen, E., Knekt, P., Härkänen, T., Virtala, E., Lindfors, O. Childhood adversities as predictors of improvement in psychiatric symptoms and global functioning in solution-focused and short- and long-term psychodynamic psychotherapy during a 5-year follow-up. J Aff Disord 2018; 235: 525534.

Fonagy, P. The effectiveness of psychodynamic psychotherapies: an update. World Psychiatry 2015; 14: $137-150$. 
Keinänen, M., Isosävi, M., Sailas, E. Mentalisaatiohoitotiimin perustaminen suomalaiseen mielenterveyden hoitojärjestelmään. Mentalisaatioterapian suomalainen kongressi [The implementation of MBT-team to Finnish Mental health practice. The Finnish Mentalization-based treatment congress]. Turku, 22.11.-23.11.2017.

Keinänen, M., Martin, M. Mieli meissä. Tasapainoa arkeen mielentämisen keinoin [The mind in us. Towards the balance in everyday life by means of mentalizing]. 2019, Helsinki: Kirjapaja.

Kela. Kelan kuntoutustilastot. Official Statistics in Finland. Social security, 2019. [Social Insurance Institution of Finland].

https://helda.helsinki.fi/bitstream/handle/10138/301382/Kelan_kuntoutustilasto_2018.pdf?sequence $=4 \&$ isAllowed $=\mathrm{y}$

Kela. Rehabilitative Psychotherapy, 2020. https://www.kela.fi/web/en/rehabilitative-psychotherapy.

Knekt, P., Laaksonen, M.A., Härkänen, T., Maljanen, T., Heinonen, E., Virtala, E., Lindfors O. The Helsinki Psychotherapy Study: Effectiveness, Sufficiency, and Suitability of Short- and Long-Term Psychotherapy. In: R.A. Levy, J. S. Ablon, H. Kächele (Eds.), Psychodynamic Psychotherapy Research: Evidence-Based Practice and Practice-Based Evidence, 2012. New York: Springer. Humana Press, pp. 71-94. https://link.springer.com/chapter/10.1007/978-1-60761-792-1_5

Knekt, P., Lindfors, O., Keinänen, M., Heinonen, E., Virtala, E., Härkänen, T. The prediction of the level of personality organization on reduction of psychiatric symptoms, and improvement of work ability in short- vs. long-term psychotherapy during a 5-year follow-up. Psychology and Psychotherapy: Theory, Research and Practice 2017; 90: 353-376.

Knekt, P., Saari, T., Lindfors, O. Intelligence as a predictor of outcome in short- and long-term psychotherapy. Psychiatry Res 2014; 220: 1019-1027.

Knekt, P., Lindfors, O. (Eds.). A Randomized Trial of the Effect of Four Forms of Psychotherapy on Depressive and Anxiety Disorders: Design, Methods, and Results on the Effectiveness of Short-Term Psychodynamic Psychotherapy and Solution-Focused Therapy During a One-year Follow-Up. Helsinki: Social Insurance Institution of Finland, 2004.

Knekt, P., Virtala, E., Härkänen, T., Vaarama, M., Lehtonen, J., Lindfors, O. The outcome of shortand long-term psychotherapy 10 years after start of treatment. Psychol Med 2016; 46:1175-88.

Knekt, P., Lindfors, O., Renlund, C., Sares-Jäske, L., Laaksonen, M.A., Virtala, E. Use of auxiliary psychiatric treatment during a 5-year follow-up among patients receiving short- or long-term psychotherapy. J Aff Dis 2011; 135, 221-230.

Laaksonen, M. A., Knekt, P., Lindfors, O. Psychological predictors of the recovery from depression or anxiety disorder in short-term and long-term psychotherapy during a 3-year follow-up. Psychiatry Res 2013: 208; 162-171.

Laurenssen, E. M. P., Luyten, P., Kikkert, M. J., et al. Day hospital mentalization-based treatment v. specialist treatment as usual in patients with borderline personality disorder: a randomized controlled trial. Psych Med 2018; S0033291718000132.

Leichenring, F., Luyten, P., Hilsenroth, M., Abbass, A., Barber, J., Keefe, J. R., Rabung, S., Steinert, C. Psychodynamic psychotherapy meets evidence-based medicine: a systematic review using updated criteria. Lancet Psychiatry 2015; 2: 648-60.

Lindfors, O., Knekt, P., Heinonen, E., Virtala, E. Self-concept and quality of object relations as predictors of outcome in short- and long-term psychotherapy. J Affect Dis 2014; 152-154: 202-211. 
Lindfors, O., Knekt, P., Lehtonen, J., Maljanen, T., Virtala, E., Härkänen, T. Effectiveness of psychoanalysis and long-term psychodynamic psychotherapy on personality and social functioning 10 years after start of treatment. Psychiatry Res 2019; 272: 774-783.

Orlinsky, D. E., Strauss, B., Rønnestad, M. H., Hill, C. Castonguay, L., Willutzki, U., Hartman, A., Taubner, S., \& Carlsson, J. A Collaborative Study of Development in Psychotherapy Trainees.

Psychotherapy Bulletin 2015; 50: 21-25.

https://www.psychotherapyresearch.org/page/SPRISTAD?A6

PALKO/COHERE. Palveluvalikoimaneuvoston suositus "Psykoterapiat ja muut psykososiaaliset hoito- ja kuntoutusmenetelmät mielenterveys- ja päihdehäiriöiden hoidossa", 1.11.2018. [Psychotherapy and other psychosocial interventions in the treatment and rehabilitation of mental disorders and substance use disorders] https://palveluvalikoima.fi/psykoterapiat-ja-muutpsykososiaaliset-hoito-ja-kuntoutusmenetelmat-mielenterveys-ja-paihdehairioiden-hoidossa.

Pylkkänen, K., Pöllänen, R., Upanne, M. (Eds.) Psykoterapia Suomessa [Psychotherapy in Finland]. Sosiaali- ja terveysalan tutkimus- ja kehittämiskeskus, Oppaita 29, 1995.

Storebo, O. J., et. al. Psychological therapies for people with borderline personality disorder. Cochrane Database Syst Rev. 2020 May 4;5:CD012955. doi: 10.1002/14651858.CD012955.pub2

Suomalainen Lääkäriseura Duodecim ja Suomen Akatemia [the Finnish Medical Society Duodecim and the Academy of Finland]. Psykoterapia. Konsensuslausuma. [Psychotherapy. Concensus statement]. 2016. https://www.duodecim.fi/wp-content/uploads/sites/9/2016/02/lausuma06.pdf

Tikkanen, T. Kelan kuntoutuspsykoterapiat jatkuvat [The rehabilitation psychotherapies funded by the Social Insurance Institution of Finland will continue]. Psykoterapia 2018; 37, 151-159.

Tuulio-Henriksson, A., Heino, P., Toikka, T., Autti-Rämö, I. Kelan työ- ja opiskelukykyä tukeva kuntoutus toteutuu eri kestoisena. [Social Insurance Institution-subsidized rehabilitation psychotherapy for persons with dysfunction in work and studying actualizes in different length]. Kuntoutus 2014; 3: 5-17.

Tuulio-Henriksson A, Toikka T, Heino P, Laukkala T. Kuntoutuspsykoterapia tukee työssä pysymistä. [Rehabilitation psychotherapy supports staying at work]. Suomen Lääkärilehti 2019; 13, 816-24.

Valkonen, J., Henriksson, M., Tuulio-Henriksson, A., Autti-Rämö, I. Psykoterapeutit Suomessa. Psykoterapiapalvelut ja niiden järjestäminen. [Psychotherapists in Finland. Psychotherapy services and their organization]. Kela, Helsinki, 74/2011. ISBN 978-951-669-858-1.

Vorma, H., Rotko, T., Larivaara, M., Kosloff, A. Kansallinen mielenterveysstrategia ja itsemurhien ehkäisyohjelma vuosille 2020-2030. [National Mental Health Strategy and Programme for Suicide Prevention 2020-2030]. Sosiaali- ja terveysministeriö, Helsinki 2020. http://URN:ISBN:978-952-004139-7.

Vuorilehto, M. S., Melartin, T. K., Riihimäki, K., Isometsä, E. T. Pharmacological and psychosocial treatment of depression in primary care: Low intensity and poor adherence and continuity $\mathrm{J}$ Affect Dis 2016; 202: 145-152.

Yakeley, J. Psychoanalysis in modern mental health practice. Lancet Psychiatry 2018; 5: 443-450. 